\title{
POLITICS IN MOTION
}

\section{SOME REFLECTIONS ON POLITICAL BIAS IN SIMULATION GAMING}

\author{
Nicklas Lundblad and Anders Frank \\ Swedish Reserach Institute for Information Technology \& Swedish Defence Materiel \\ Administration
}

\begin{abstract}
Is there political bias in simulation games? We examine two popular games and show that there are indeed political statements in these games, but that they form no coherent political theory. So the answer is yes - there are many political statements, but no single theory or simple bias. We then also suggest that the implementation of politic will become more important over time, as demands for realism increase.
\end{abstract}

Key words: simulation, modelling, politics, law, game architecture

\section{Introduction}

This paper deals with the issue of politics in simulation games. Our basic question has been if there is reasonable evidence to suggest that there is some political bias in simulation games.

Politics - built into the very architecture of the simulation games - is an important component in the construction of simulation games. If there is political bias in them this would suggest a number of different problems, from how they affect people playing them (is SimCity indoctrination?) to whether this is a conscious effort on behalf of the game industry or not. The paranoia in these questions is not necessarily strange, considering that many young people today play these games over long periods of time.

We have concentrated on two games in this paper: Empire Earth and Civilisation III. We have also - as mentioned - decided to include the manuals in our analysis, since they offer valuable quotations and examples to work with.

The original version of this chapter was revised: The copyright line was incorrect. This has been corrected. The Erratum to this chapter is available at DOI: 10.1007/978-0-387-35660-0_65 
During our work it became clear to us that the question of political bias must be dealt with in a two-step model. The first question we must ask is whether there are political statements and presuppositions apparent in the game, and the second question is if these are consistent with not only scattered political beliefs, but a coherent political theory. We call games with the first quality for politically infused games, and games with the second quality politically tendentious.

We would also like to acknowledge that we know that there are theories that state that the computer medium in itself fosters playfulness, and that these games should not be taken seriously [Danet 2001]. Our research is not aimed at correcting political bias, but rather at understanding it.

\section{Macro Model Issues}

We also distinguished two different levels of analysis of the politics of simulation gaming. One is the analysis of issues pertaining to the macro level - i.e. issues of the possibility of modelling society, of controlling it and other related questions. The other level is the micro level, where we typically ask if a certain measure always will accomplish a certain result (i.e. will lowering taxes make people more productive, and actually raise the amount collected from taxes as the theory of the the Laffer curve implies?).

Both micro and macro level issues must be analysed in trying to find the possible political bias inherent in the different simulation games. We will begin by discussing some macro level issues.

\subsection{The possibility of simulation}

It can be argued that the very idea that a society can be simulated relies on a political theory. Some political theorists, noticeably Hayek, would probably resist the idea that a society can be illustrated as a model with a set of factors that can be used to decide the evolution of that society [Hayek 1999(1959)].

In Civilisation III the number of factors - or 'impulses' - is reduced to five: Exploration, Economics, Knowledge, Conquest and Culture.

The factors in Empire Earth are very much the same - but less complicated, and more focussed on the military aspects. Arguably, these are not simple factors, however. But can civilisation be thus modelled?

Hayek's view would perhaps instead be that society is the result of a number of spontaneous processes slowly organising into complex patterns, and that these are complex enough to resist simple simulation, and that 
perhaps it is not possible to enumerate the driving forces in the way that the game does so.

Other political theorists, such as Marx, would presumable argue that it is simple to simulate society, and that the model he offers in his collected works is an example of such a simulation - and that anyone who argues differently is neglecting the Hegelian patterns apparent in history [Marx 1848]. For Marx it would presumably then be less controversial to enumerate the driving forces, even though he would not agree to the enumeration in civilisation. Marx set of factors would probably exclude many of the phenomena that he felt was not driving forces, but rather concurrent effects of the basic economic development.

On the other hand Hayek would probably argue that it is possible to simulate societies by using complex, and spontaneous processes and Marx would resist the idea that the evolution of society is so variable as to be the object for simulation. Hayek could very well be content with the factors enumerated in Civilisation III, if it were made clear that they are indeed complex and not finally analysable in any simple manner. In Marx view there are not many possible paths for a society, but rather one path, determined by historical materialism. Most political analysis of the 'impulses' would probably also center on the insight that these 'impulses' are interdependent.

So is the idea that society can be simulated a political idea? Yes, without a doubt, but it is a very complex political idea and it can be interpreted in any number of ways. There is no cheap political bias available in this idea; but rather a complex and deeply problematic political theory that could be explained in both leftist and right-wing ways.

\section{$2.2 \quad$ The possibility of control}

It could also be argued that the very idea of 'playing' or controlling a society is political in a certain extent. Again, the difference between the perspective offered by Hayek and that of Marx suffices to give us examples of this. Hayek explicitly states that as much as possible should be left to spontaneous processes, and that welfare engineering will fail, since it tries to control processes better left to self-evolve according to the theory of the invisible hand as this was put forward by Adam Smith [Hayek 1999(1959), Smith 1776]. Marx on the other hand argues that society must be controlled and planned, and that it will be necessary to control the assets of any given society.

But things are not so simple. Marx would probably resist the idea that historical evolution from one state of society to another could be controlled, and even perhaps, chosen. Here he would argue that there is a certain amount 
of necessity in the evolution from capitalism to communism, for example, and that this cannot be subject to doubt. Hayek, on the other hand, would argue that it is quite possible to make individual choices and plans, and thus that those plans can be simulated and controlled - as they indeed are by individuals in the liberal model of the world.

So is the idea that societies and civilisations can be played a political idea? Well, yes, to a certain point -but it is also a complex political idea, and it is hard to state that it is simple a left or right idea.

\subsection{The evolution of civilisations}

The idea that civilisations evolve from one stage to another is always present in simulation games. New technologies and means of production make it possible for a civilisation to step up from one stage of civilisation to the next.

This idea, of the sophistication of civilisations, and their life and death, is also curiously political. It offers a spenglerian theme, ripe with connotations from biology, of born, living and dying societies [Spengler 1996(1918)].

Clearly not all political ideologies would agree with this rendering of societies as evolving. Some political ideologies support the view that there are necessary historical stages that societies go through (Marxism being the most obvious example), while others - like liberalism - seem more averse to this idea.

In Civilisation III all civilisations progress or can progress through the following stages of government: Anarchy, Despotism, Monarchy, Republic, Communism and Democracy.

The paths through these different forms can vary, and some players might opt to skip some stages. In Empire Earth it is possible to go through even more stages and ages, which are more related to the underlying technologies (or means of production), than to the forms of government.

The different forms of government/ages are not explicitly valued, but some values are apparent in the descriptions of the governments in question. The handbook describes democracy in the following way:

"You rule as the elected executive of a modern Democracy. The people feel that you rule because they chose you. The degree of freedom allowed under this government results in the maximum opportunity for economic production and tax income. However, the people also have a very strong voice in determining how much economic production is devoted to improving the standard of living. Maintaining a military force in the field comes with great political and economic costs."

1 Civilisation III, manual, p130 
This description is laden with political statements, but does it express a coherent political theory? For example: the reference to the maximisation of production under the degree of freedom allowed seems to implicate a liberal view of the economy. If people are free they produce more. On the other hand the reference to people determining how to improve the standard of living seems to assume that the standard of living is set by some sort of welfare government, and thus to imply that the degree of financial freedom is, then, not so great after all. The references to the people, implying that they "feel" that thy chose you, are also ambiguous. That it would be more expensive to keep an army is also an interesting conclusion that seems to imply that democratic societies, somehow, are resistant to, or unable o sustain an effort of, war. This impression is also strengthened by the special condition added to democracy that states that:

"War weariness [...] has profound negative effect on your citizens' happiness. In fact, if you remain at war for too long, your Democracy can fall into Anarchy."

Other forms of government are also described in a manner that makes it difficult to discern a single ideology. Take the government form of communism:

"You are the head of a communist government, and you rule with the support of the controlling party. Although this form of government allows more production than Despotism, the orthodoxy of the party restricts personal and economic freedom, limiting tax income. On the positive side, corruption is negated by he action of local party apparatus, the army and secret police suppress most dissent, and your large security forces recruit excellent spies."

This rendition of communism seems rather hostile to the concept, and accepts many of the conventional criticisms of the basic ideology of Marxism, or Leninism. This is certainly not the description of communism found in Marx's writings[Marx 1848]:

" Communism deprives no man of the power to appropriate the products of society; all that it does is to deprive him of the power to subjugate the labour of others by means of such appropriations."

But subjugation and depriving the citizens is exactly what the government form in Civilisation III does. It is quite obvious that there is some political angle in the description of communism. ${ }^{3}$ However, that does not sum up to a coherent political theory.

\footnotetext{
${ }^{2}$ Civilisation III, manual, p 131

${ }^{3}$ It also becomes, inadvertently to be sure, rather funny when the effectiveness of suppressing dissent is put down on the positive side. This is, of course an effect of the values being focussed on playability rather than on human rights - and not especially surprising.
} 


\section{Micro Model Issues}

There are also micro issues, which concern the relationships between societal facts as these are expressed by the games in question. These issue are more easy to situate in certain political theories, but often remain rather fuzzy.

\subsection{National identities}

Almost all civilisation simulations that deal with real civilisations have a tendency (necessary to make the world view it proposes playable) to simplify. Characteristically this tendency comes out in the categorisation of the different, available civilisations that can be played.

In Civilisation III the different civilisations are characterised as having qualities and starting advances. In some cases these become slightly prejudiced. The Germans, for example, are described as having qualities of science and military and the British are described as "expansionist and commercial". ${ }_{4}$ Empire Earth features similar short cuts for starting civilisations, and offer up similar prejudices.

These simplified and prejudiced descriptions are based on the idea that it is possible to reduce entire nations to some sort of national character - a belief remnant from the romantic ages. It has a political home in extreme forms of political thinking, such as fascist and national-socialist writings.

\subsection{Taxes}

How does tax pressure relate to the happiness of citizens in the two games? In Civilisation III the model of how taxes and financial systems work is highly simplified. (It is - for example, not possible to run a civilisation with a negative result and a depleted treasury, thus excluding the possibilities of international loans and expansive periods with high rates of debt - factors that in fact could increase the playability of the game)

The political view of taxes is simple in Civilisation III. Taxes are collected to cover up expenses, and if the tax pressure is too high it will produce unhappiness. In Empire Earth there is no clear division between what is being taxed, and what is not. All money is subject to the players choice.

This has some liberal connotations, but not enough to merit it being called political bias.

\footnotetext{
${ }^{4}$ Seep 17 , Civilisation III Handbook.
} 


\subsection{The view of technology}

Another apparent fact in these games is that there is a certain role for technology to play. Technological determinism is an ideology that runs strong in the simulation games. While hard to place in a traditional left-right scale, this view of technology (with technology trees and technology advances), is clearly politically ambiguous. Theories of technology and society abound, and some of the more marxist or socialist interpretations of technology would resist this image. [Feenberg 2001]

\section{The Gaming Experience and Political Bias}

It is probably impossible to make a simulation game without politics of some kind. The idea of playing a society - even if it is, as in Empire Earth, primarily the militaristic parts of a society - is inherently political, and forces the game designer to make a number of political choices.

When choosing what political hypotheses to use in the model of the world being constructed, it is important to set up a number of criteria that maximise the gaming experience.

In the trade-off between realism and playability it is important not to make too many concessions to realism - even if the trend is going that way. Too complex society models would not be enjoyable to play.

In our investigations we have felt that there is still some room for expanding on the political models of games today, and we especially think that the players will welcome more complex underlying models.

We also formulated another question, which we feel merits some discussion, and that is if there are any criteria for evaluating the entertainment value of political ideologies. We have - based on our experience - listed a number of criteria:

1) Strong possibilities of control. Laissez faire-models are less interesting than those that suggest that a strong ruler can really change things.

2) Clear distribution of power. In playing games it is important to be able to assess power relations to make informed decisions.

3) Simple economic functions. This is essentially a consequence of 1). If there are no strong functions and clear cause-and-effect-relations, it becomes hard to play.

In view of this it seems possible that authoritarian ideologies like som flavours of Marxism and conservatism are more entertaining to use in play than the more extreme forms of liberalism. At the same time it would be 
interesting to examine what would happen if the political model allowed for leaving much of what is produced to be handled by the citizens themselves.

We feel that the continuing evaluation of available political models will be important work for those wishing to use political models to add entertainment value to simulation games.

\section{Conclusions and Further Research}

Our conclusions in analysing the two individual games in this study are two: the first is that there are indeed politically biased statements in these games. The second is that these statements do not form a coherent political theory. These games are, in other words, politically infused but not politically tendentious.

Simulation games do not express liberal or Marxist theories, but rather clusters of statements that can be interpreted as belonging in the different political fields. When building in politics in the very architecture of the games it seems important to choose such statements that heighten the gaming experience.

We have suggested that some ideologies - typically laissez faire idealism - lack entertainment value in that they do not open up for control and simulation in the same way as other ideologies with more authoritarian views (i.e. conservatism and Marxism) do.

In expanding this research we are aiming to examine on-line role playing games and the politics formed in these game by the interaction of a multitude of gamers. These games offer the rare sociological possibility of observing the birth and growth of legal, political and ethical frameworks in a slowly forming society.

\section{References}

Civilisation III and Manual

Danet, Bredna [2001] Cyberplay: Communicating On-line (Berg 2001)

Empire Earth and Manual

Feenberg, Andrew [2001] Transforming Technology: A Critical Theory Revisited (Oxford 2002)

Hayek, Friedrich von [1999] Frihetens Grundvalar (in Swedish) (Stockholm 1999)

Marx, Karl [1848] The Communist Manifesto

Smith, Adam [1776] The Wealth of Nations

Spengler, Oswald [1996] Västerlandets undergång (in Swedish) (Stockholm 1996) 